\title{
On the Development and Characterization of a Reduced Scale Continuous Feed Firebrand Generator
}

\author{
SAYAKA SUZUKI, and SAMUEL L. MANZELLO \\ Fire Research Division, Engineering Laboratory \\ National Institute of Standards and Technology (NIST) \\ 100 Bureau Drive, Gaithersburg, MD 20899-8662 USA
}

\begin{abstract}
A new experimental apparatus, known as the NIST Reduced Scale Continuous Feed Firebrand Generator (the NIST continuous feed Baby Dragon) is presented. This version of the Firebrand Generator is based upon the NIST Dragon, the only experimental device capable of generating controlled firebrand showers. The unique features of the continuous feed Baby Dragon, as opposed to the present NIST Dragon, is the capability to produce a constant firebrand shower in order to expose building materials to continual firebrand bombardment. An experimental series was conducted to determine the range of operating conditions for this device. Wood pieces were fed into the device using a conveyer system, ignited using a propane burner, and a blower was used to loft the generated firebrands. The number flux and mass flux were measured as a function of feeding rate to determine optimum conditions to generate steady firebrand showers. It was observed that a feeding rate of 15 pieces $(34.6 \mathrm{~g} / \mathrm{min})$ provided the most constant and uniform continuous firebrand production. Measurements of heat release rate (HRR) were conducted to make sure the device provided low HRR in order to determine if it may be considered for use by testing laboratories in a safe manner. Finally, the firebrand size and mass produced using the newly developed device presented in this paper are commensurate to those measured from full-scale tree burns and actual WUI fires.
\end{abstract}

KEYWORDS: firebrand showers, wildland-urban interface fires, ignition.

\section{INTRODUCTION}

Fires in the wildland-urban interface (WUI) have been a large problem not only in the USA, but all over the world. WUI fires have caused significant damage to communities and some examples of this destruction occurred in Florida (1998), Southern California (2003, 2007, 2008), Greece (2007), and Australia (2009). Post-fire studies suggest that the firebrands are a major cause of structural ignition of WUI fires in USA and Australia [1-3].

In order to develop scientifically based mitigation strategies, it is necessary to understand the vulnerabilities of structures to firebrand showers. While firebrands have been studied for some time, most of these studies have been focused on how far firebrands fly [4-14]. Unfortunately, very few studies have been performed regarding firebrand generation [15-17] and the ultimate ignition of materials by firebrands [18-21].

Recently Manzello et al. [17, 22-25] developed an experimental apparatus, known as the NIST Firebrand Generator (NIST Dragon), to investigate ignition vulnerabilities of structures to firebrand showers. The NIST Firebrand Generator is able to generate a controlled and repeatable size and mass distribution of glowing firebrands. The experimental results generated from the marriage of the NIST Dragon to the Building Research Institute's (BRI) Fire Research Wind Tunnel Facility (FRWTF) have uncovered the vulnerabilities that structures possess to firebrand showers for the first time [25]. These detailed experimental findings are being considered as a basis for performance-based building standards with the intent of making structures more resistant to firebrand attack.

Naturally, full-scale experiments are required to observe the vulnerabilities of structures to firebrand showers but reduced-scale test methods afford the capability to evaluate firebrand resistant building elements and may serve as the basis for new standard testing methodologies. To this end, Manzello et al. [26,27] developed the NIST Dragon's LAIR (Lofting and Ignition Research) facility to simulate wind driven firebrand showers at reduced-scale. This facility consists of a reduced-scale Firebrand Generator (known as the NIST Baby Dragon) coupled to a bench-scale wind tunnel. The reduced-scale Dragon's LAIR facility was able to reproduce the results obtained from the full-scale experiments conducted pertaining to firebrand penetration through building vents. 
While the NIST Dragon's LAIR facility and the full-scale NIST Dragon coupled to BRI's FRWTF have been used to expose building elements to firebrand showers, the duration of exposure using the existing apparatus is limited. To develop test methods needed to evaluate different building elements resistance to firebrand showers requires the capability to generate firebrand showers of varying duration.

Accordingly, the NIST reduced-scale continuous feed Firebrand Generator (the NIST continuous feed Baby Dragon) has been developed to remedy this problem. The unique features of the NIST continuous feed Baby Dragon, as opposed to the present NIST Dragon, are the ability to produce a constant firebrand shower in order to expose building materials to continual firebrand bombardment. An experimental series was conducted to determine the range of operating conditions for this new device. Wood pieces (to simulate firebrands) were fed into the device using a conveyer system and ignited using a propane burner to generate firebrands. The number flux and mass flux were measured as a function of feeding rate to determine the optimum conditions to generate steady firebrand showers.

\section{EXPERIMENTAL DESCRIPTION}

The experimental apparatus is shown in Fig. 1. This version of the device is modified from the NIST Baby Dragon [26, 27] and consisted of two parts; the main body and continuous feeding component. The feeding part was connected to the main body and had two gates to prevent fire spread. Each gate was opened and closed alternatively. A blower was connected to the main body. All components of the Firebrand generator were constructed of stainless steel.

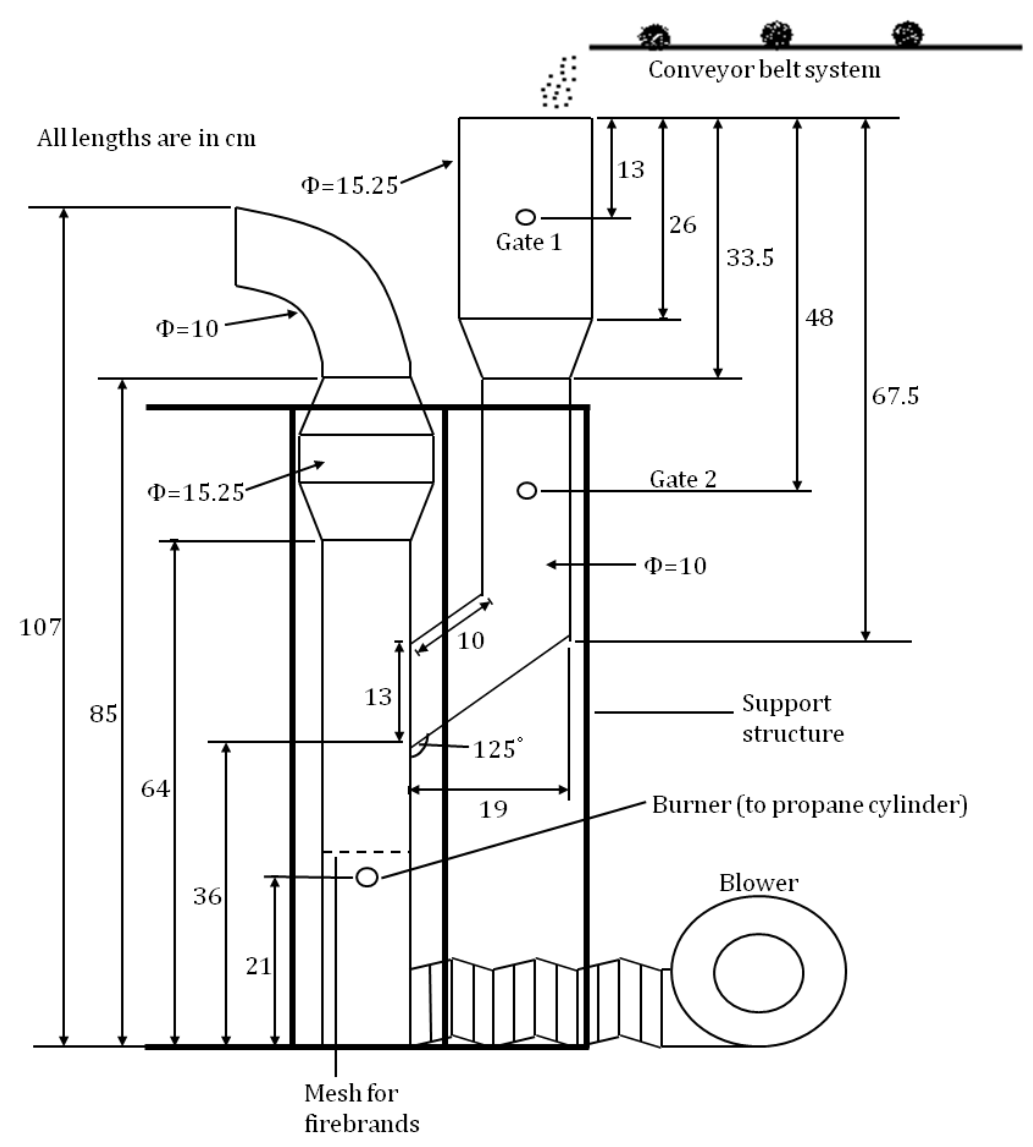

Fig. 1. Schematic of NIST Continuous Feed Baby Dragon (side view).

A conveyer was used to feed wood pieces continuously into the device. The conveyer belt was moving at $1.0 \mathrm{~cm} / \mathrm{s}$, and wood pieces were put on the conveyer belt at $12.5 \mathrm{~cm}$ intervals (see Fig. 2). In each experiment, the number of wood pieces placed on the conveyer belt was varied to determine the most efficient feeding rate. For all tests, Douglas-fir wood pieces machined with dimensions of $7.9 \mathrm{~mm}(\mathrm{H})$ by $7.9 \mathrm{~mm}(\mathrm{~W})$ by $12.7 \mathrm{~mm}(\mathrm{~L})$ were used to produce firebrands. The reasons for using wood pieces for these 
experiments were: (1) the use of wood pieces would be easier for other testing laboratories to obtain and (2) due the small amount of wood required it was quite easy to produce these pieces for the reduced-scale tests. These same size wood pieces were used in past studies and have been shown to be commensurate with sizes measured from full-scale burning trees as well as distributions obtained from actual WUI fires [2628].

An important operational parameter that was varied was the blower speed. When the blower was set to provide an average velocity below $4.4 \mathrm{~m} / \mathrm{s}$ measured at the exit of the Dragon when no wood pieces were loaded, insufficient air was supplied for combustion and this resulted in a great deal of smoke being generated in addition to firebrands. Above $4.4 \mathrm{~m} / \mathrm{s}$, smoke production was mitigated but then the firebrands produced were in a state of flaming combustion as opposed to glowing combustion. It has been suggested that firebrands fall at or near their terminal settling velocity. As such, when firebrands contact ignitable fuel beds, they are most likely in a state of glowing combustion, not open flaming [8]. It is possible for firebrands to remain in a flaming state under an air flow and, it is reasonable to assume that some firebrands may still be in a state of flaming combustion upon impact. The purpose of this device is to simulate firebrand showers observed in long range spotting and therefore glowing firebrands were desired.

The experiments were conducted in the following manner. The blower was set at $4.4 \mathrm{~m} / \mathrm{s}$ and one propane burner was ignited and inserted into the side of the device. The propane burner was kept on continuously during the experiment. The conveyer was then switched on and wood pieces started to be fed. A certain amount of wood pieces were fed into the stainless-steel pipe first, and then the gate near the conveyer was opened. The wood pieces then fell on top of the other gate. The gate near the conveyer was then closed, and the other gate was then opened to allow the wood pieces to fall into the Dragon for ignition. Feeding continued for various durations; $5 \mathrm{~min}, 10 \mathrm{~min}$, etc. The experiments were recorded using a digital video recorder (30 frames per second) for subsequent analysis (described below).

Four different loadings of wood pieces were used to test the NIST Reduced Scale Continuous Feed Baby Dragon; 15, 30, 35, and 40 pieces. The mean and the standard deviation of mass of 15, 30, 35, and 40 pieces were: $7.2 \pm 0.2 \mathrm{~g}$ for 15 pieces $(34.6 \mathrm{~g} / \mathrm{min}), 14.4 \pm 0.1 \mathrm{~g}$ for 30 pieces $(69.1 \mathrm{~g} / \mathrm{min}), 16.9 \pm 0.6 \mathrm{~g}$ for 35 pieces $(81.1 \mathrm{~g} / \mathrm{min})$, and $19.1 \pm 0.2 \mathrm{~g}$ for 40 pieces $(91.7 \mathrm{~g} / \mathrm{min})$, respectively. For completeness a photograph of device producing firebrands is shown in Fig. 3.

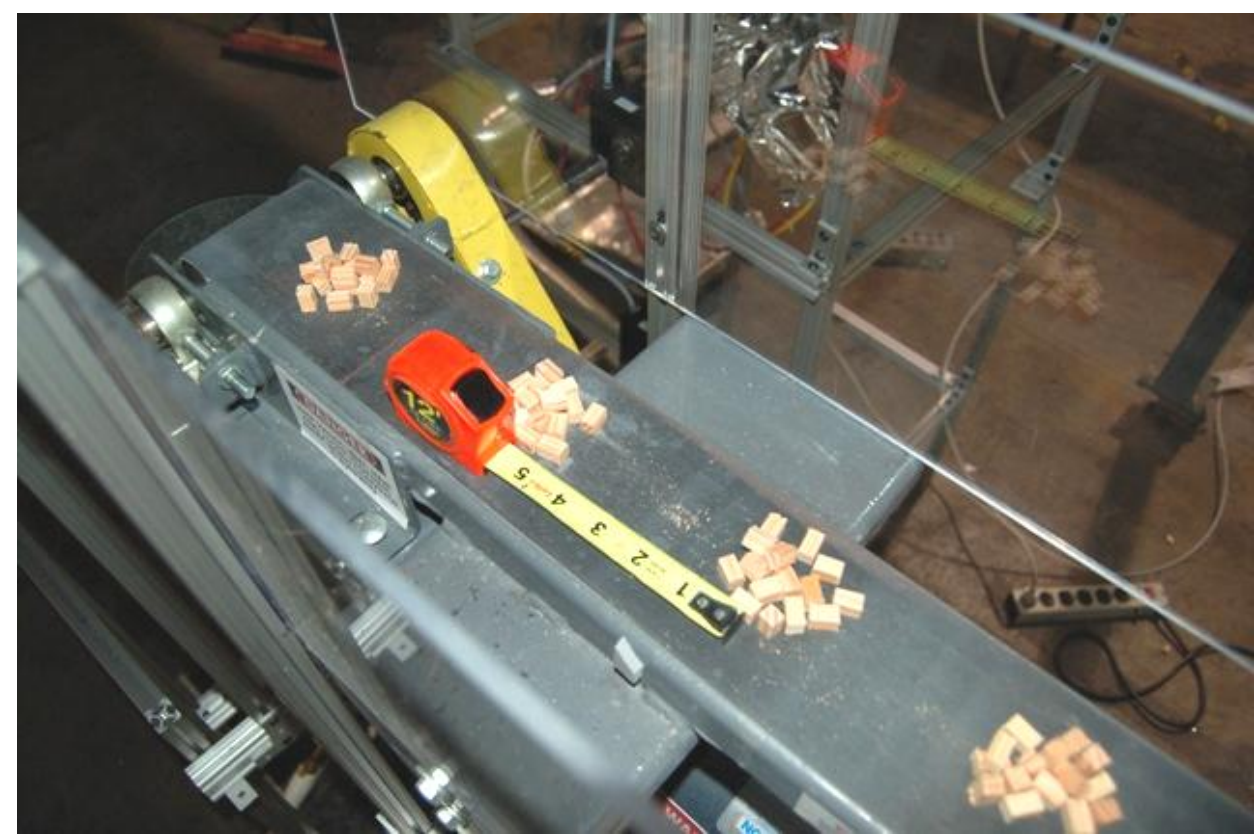

Fig. 2. Picture of the feeding process; 15 wood pieces are shown and are spaced at $12.5 \mathrm{~cm}$. 


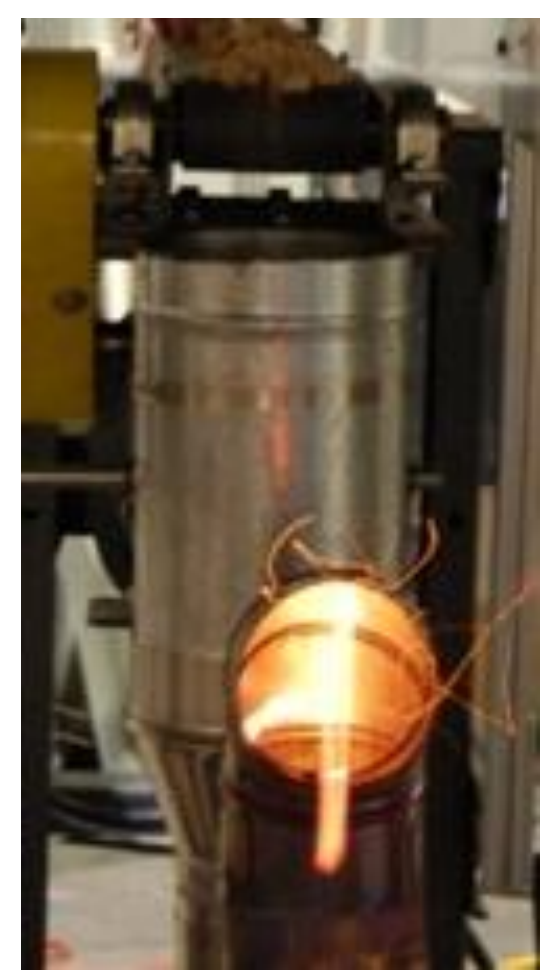

Fig. 3. Image of firebrands shower at exit of device.

\section{RESULTS AND DISCUSSION}

A parametric study was conducted to determine the range of operating conditions for this new device. The number flux, mass flux, and HRR were measured as a function of feeding rate to determine the optimum conditions to generate steady firebrand showers.

\section{Number Flux}

The number flux, at the exit of the device, was measured at a feeding rate $15,30,35$, and 40 pieces. These results are shown in Fig. 4. Time zero was set as the time when the propane burner was inserted into the generator. To determine the number flux, the number of firebrands was counted at every frame of a video recording, summed up every second, and then summed up again at every ten seconds (Figs. 4a-d). Figures $4 \mathrm{a}-\mathrm{d}$ display both the spontaneous number fluxes at every ten seconds and a 60 second-moving average number flux at every ten seconds; namely the number of firebrands over $60 \mathrm{~s}$ was summed up and then divided by six.

Based upon the observations, very few firebrands were launched from the Dragon's mouth around $60 \mathrm{~s}$ after ignition. Then, firebrand production varied in the following manner: increased rapidly, reached a peak, decreased slightly, and then maintained a constant value (15 pieces) or kept changing around a certain value (30,35, and 40 pieces). Since the purpose of the device was to produce firebrands constantly, a feeding rate of 15 pieces $(34.6 \mathrm{~g} / \mathrm{min})$ was found to be the optimal feeding rate. 


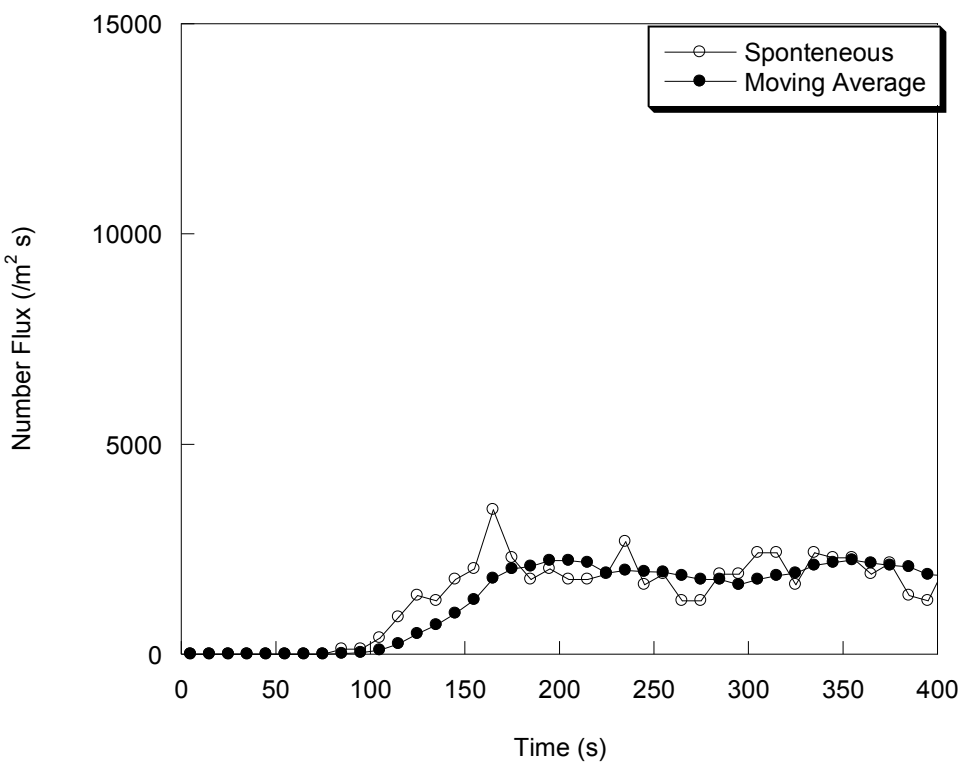

Fig. 4. (a) Feeding rate 15 pieces $(34.6 \mathrm{~g} / \mathrm{min})$.

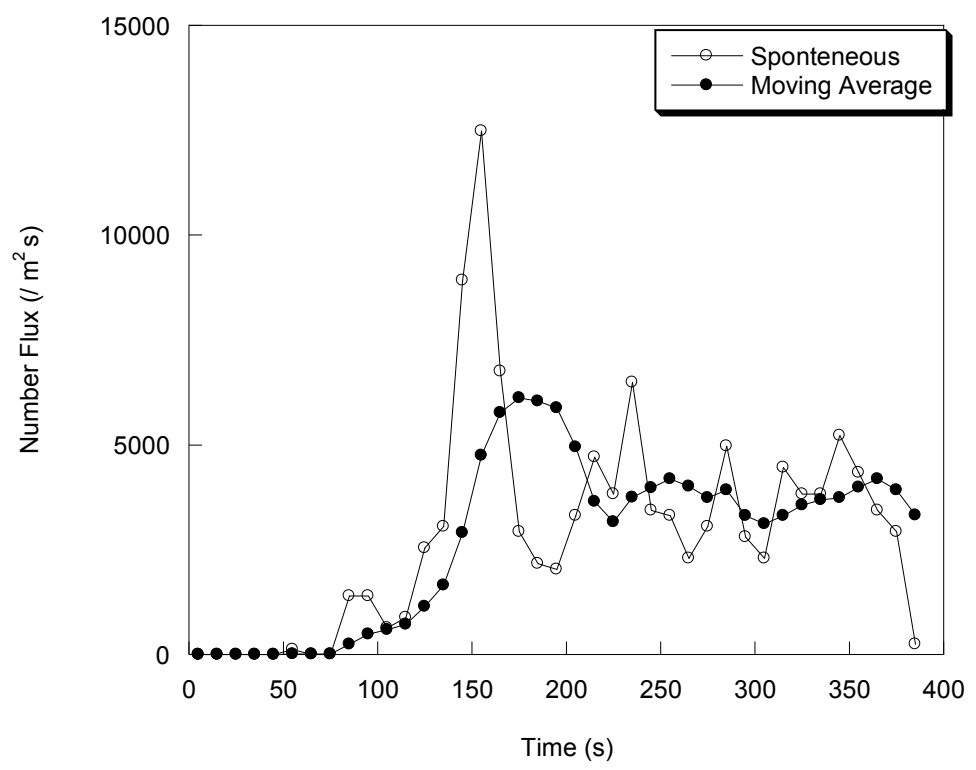

Fig. 4. (b) Feeding rate 30 pieces $(69.1 \mathrm{~g} / \mathrm{min})$. 


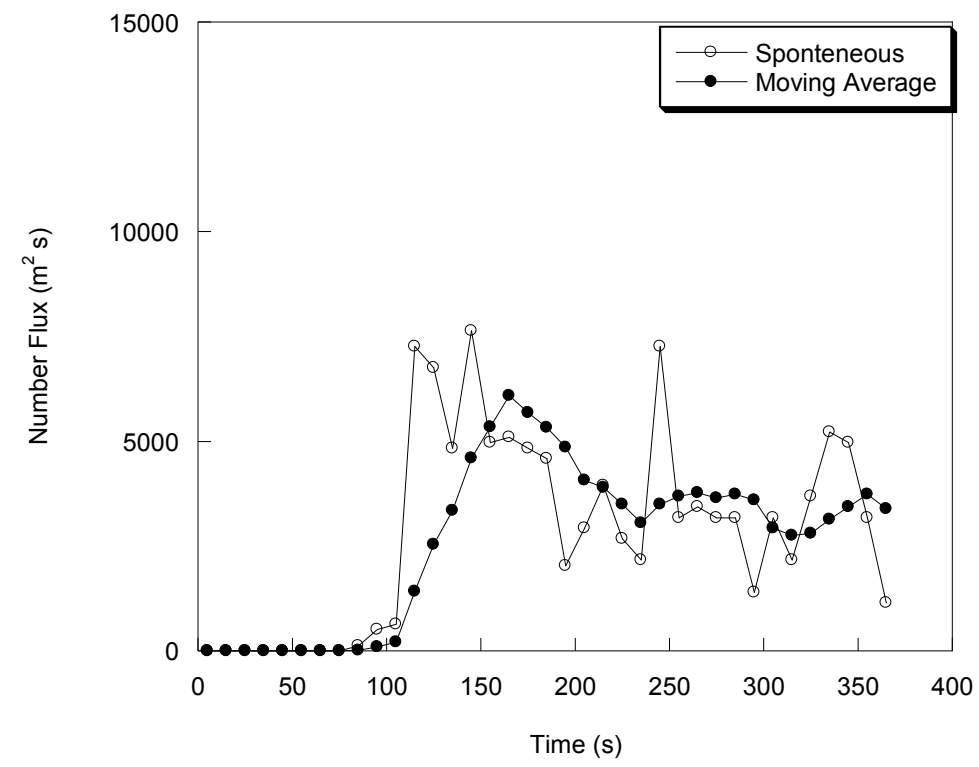

Fig. 4. (c) Feeding rate 35 pieces $(81.1 \mathrm{~g} / \mathrm{min})$.

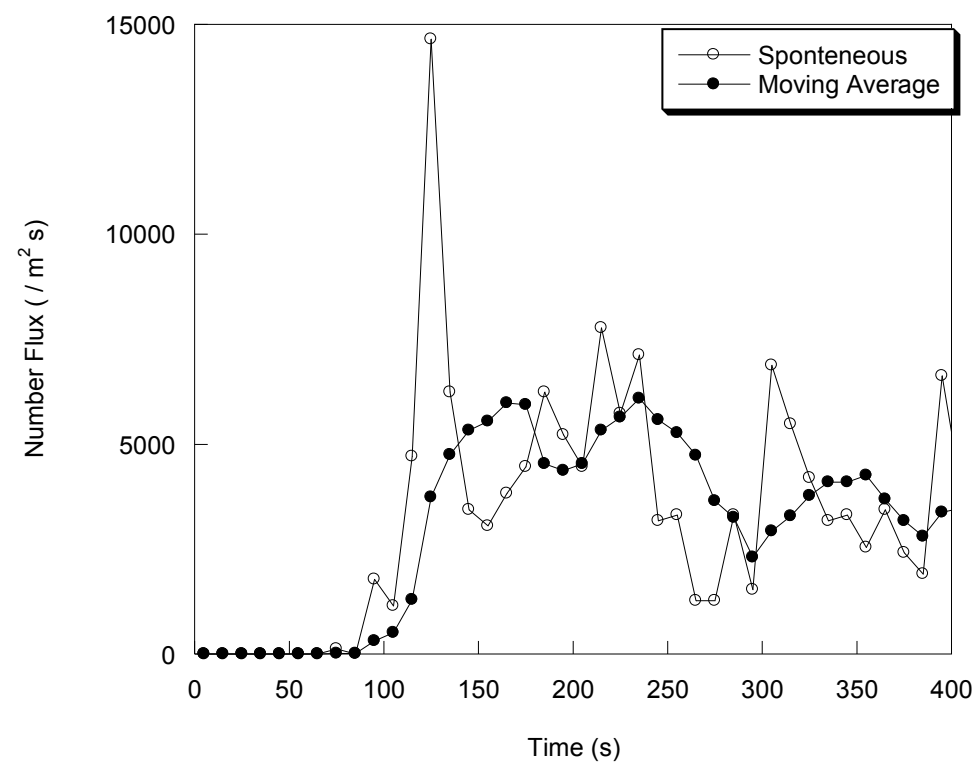

Fig. 4. (d) Feeding rate 40 pieces (91.7 g/min).

\section{Mass Flux}

Mass flux data were calculated by multiplying the number flux and the average mass of each firebrand at feeding rates of 15,30 and 35 pieces. To measure the firebrand mass, a series of water pans were placed downstream of the NIST Reduced Scale Continuous Feed Baby Dragon after firebrand production reached steady conditions. Water pans were required in order to quench combustion of the firebrands. If the water pans were not used, the firebrands would continue to burn and by the time collection was completed; only ash remained.

After the experiment was finished, the pans were collected and the firebrands were filtered from the water using a series of fine mesh filters. Firebrands were dried in an oven, at $104{ }^{\circ} \mathrm{C}$, for four hours. The mass and dimension of each firebrand was measured using precision calipers $(1 / 100 \mathrm{~mm}$ resolution) and a precision balance $(0.001 \mathrm{~g}$ resolution). The mean mass and standard deviation of each firebrand was 
obtained at each feeding rate; $0.03 \pm 0.006 \mathrm{~g}$ for 15 pieces, $0.04 \pm 0.007 \mathrm{~g}$ for 30 pieces, and $0.04 \pm 0.007 \mathrm{~g}$ for 35 pieces. The average firebrand mass was observed to be larger as the feeding rate was increased.

Figure 5 displays the mass flux at feeding rates of 15,30 , and 35 pieces. The mass flux for a feeding rate of 15 pieces was observed to be constant after an initial peak and for feeding rates of 30 and 35 pieces displayed a fluctuating pattern after the initial peak. The NIST Reduced Scale Continuous Feed Baby Dragon was able to produce around $0.05 \mathrm{~g} / \mathrm{s}$ of firebrands, based on at feeding rate of 15 pieces $(34.6 \mathrm{~g} / \mathrm{min})$ which was found to be the best feeding rate for this device. Since the number flux was very unsteady for a feeding rate of 40 pieces, the mass flux was not even measured under these conditions.

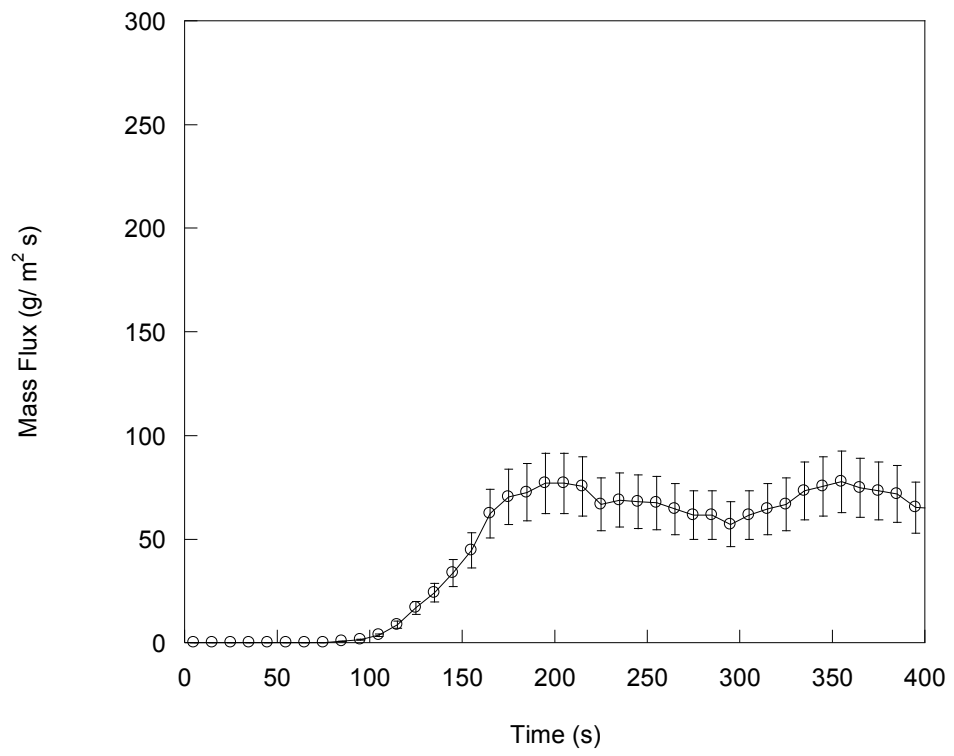

Fig. 5. (a) Feeding rate 15 pieces ( $34.6 \mathrm{~g} / \mathrm{min})$.

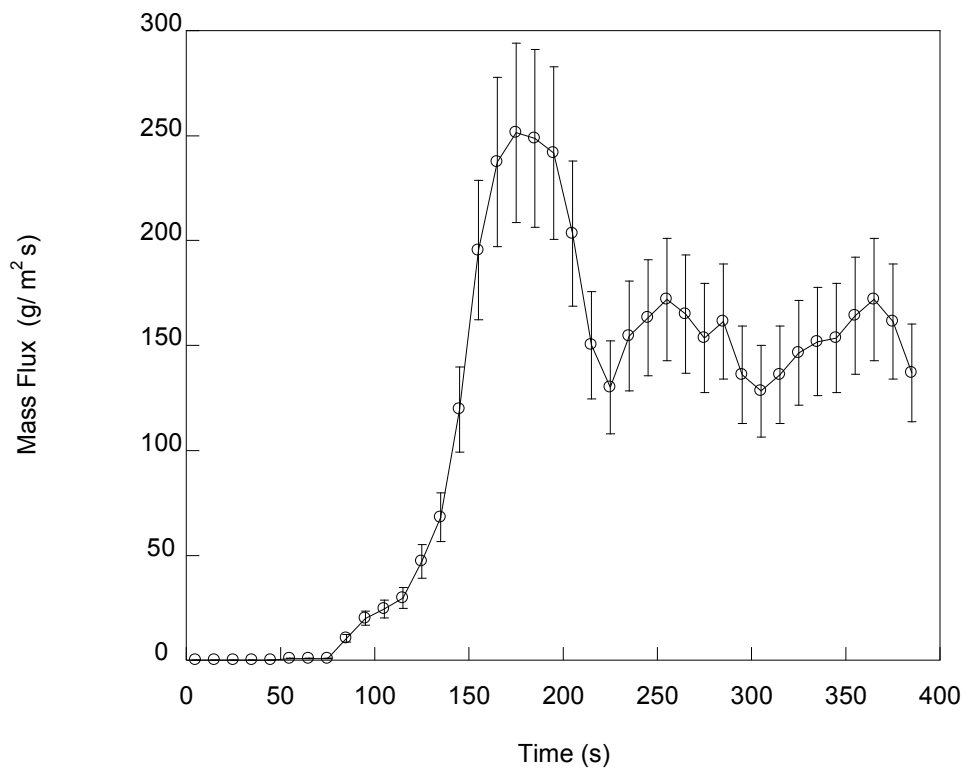

Fig. 5. (b) Feeding rate 30 pieces (69.1 g/min). 


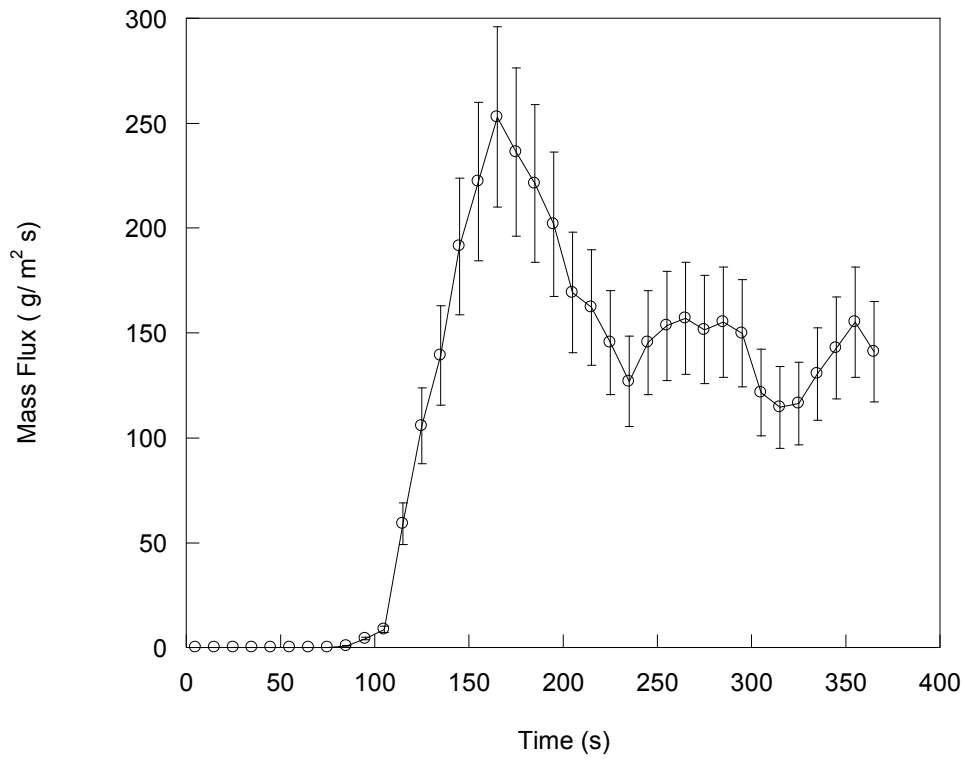

Fig. 5. (c) Feeding rate 35 pieces (81.1 g/min).

\section{Heat Release Rate}

In order for other testing laboratories to consider using the NIST Continuous Feed Baby Dragon, it is important to determine that the device can be operated safely with minimal heat release rate (HRR). Therefore, the heat release rate (HRR) for the NIST Continuous Feed Baby Dragon was also measured as a function of feeding rate. To do this, the entire apparatus was placed under the furniture calorimeter in the NIST Large Fire Laboratory (LFL) to determine the HRR using oxygen consumption calorimetry [29]. Using the methodology outlined in [29], the combined standard uncertainty of the peak HRR was determined to be $8 \%$. These results are shown in Fig. 6. For feeding rates of 15, 30, and 40 pieces (34.6, 81.1 , and $91.7 \mathrm{~g} / \mathrm{min}$ respectively), it was observed that the HRR was nearly constant within a certain period after intense heat appeared. Intense heat appeared at the time when the flame first appeared after ignition. After the initial flame appeared, the flame became smaller once the firebrands were produced.

The peak HRR and average HRR are shown in Table 1. Both peak HRR and average HRR have increased as more pieces were fed into the device. For the optimal feeding rate of 15 pieces $(34.6 \mathrm{~g} / \mathrm{min})$, the peak and average HRR was low suggesting this device can easily be operated in a safe manner.

Table 1. Peak heat release rate and average heat release rate.

\begin{tabular}{|c|c|c|}
\hline $\begin{array}{c}\text { Feeding rate } \\
\text { (pieces) }\end{array}$ & $\begin{array}{c}\text { Peak heat release rate } \\
(\mathbf{k W})\end{array}$ & $\begin{array}{c}\text { Average heat release rate } \\
(\mathbf{k W})\end{array}$ \\
\hline 15 & 17.40 & 12.9 \\
\hline 30 & 29.7 & 19.8 \\
\hline 40 & 34.5 & 23.7 \\
\hline
\end{tabular}




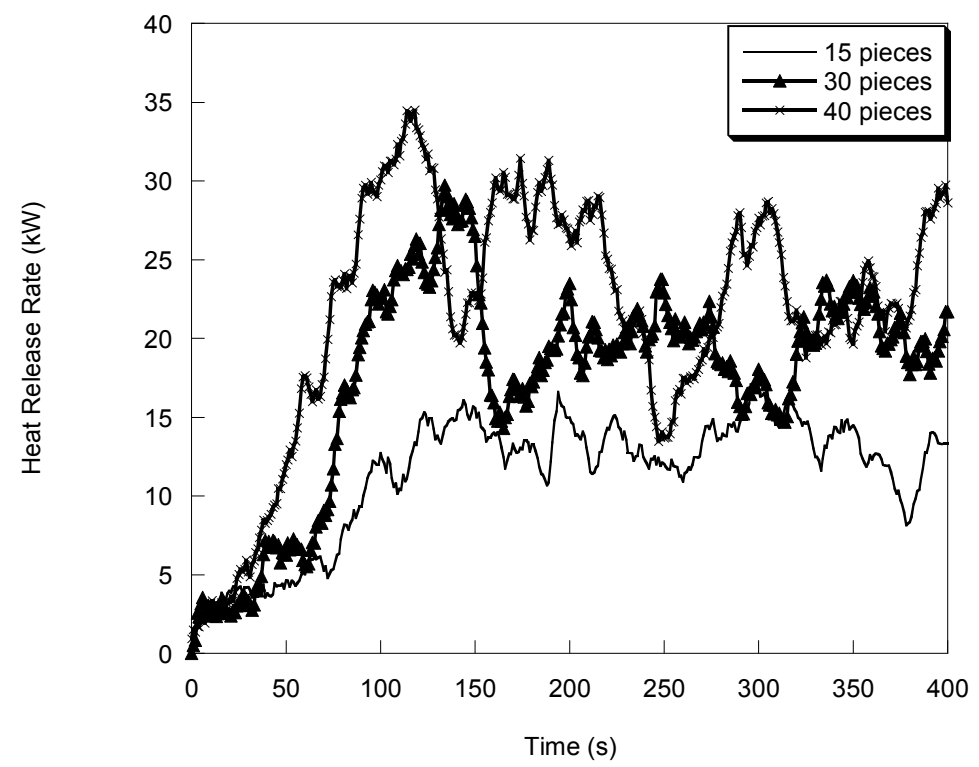

Fig. 6. Heat release rate at different feeding rates.

It is important to consider the advantages of the new experimental device presented in this paper by placing it in the context of current test standards focused on reducing ignition of structures by firebrand showers. At present, a standard exists to test ignition of roofing decks to firebrands (e.g. ASTM E108 [30]) by placing a burning wood crib on top of a section of a roof assembly under an air flow. A roofing assembly is rated based on its ability to resist ignition to the size of the firebrand placed on the roof deck (Class A, Class B, and Class C firebrand; Class A is the largest). While firebrand showers have been observed in actual WUI fires over and over again, in this standard, the dynamic process of multiple firebrands attacking the roof deck as a function of time is not taken into account. In addition to not simulating a dynamic firebrand attack, no attempt is made to relate the size and mass of the firebrand used in this standard to actual firebrands produced from burning vegetation and structures.

To support these arguments, NIST has shown the danger of a dynamic firebrand attack for ceramic tile roofing assemblies [25] using full-scale experiments. Based on those experiments, it was observed that ceramic tile roof assemblies (most ignition resistant roofing under ASTM E108 [30] for Class A firebrands) were vulnerable to ignition from a dynamic firebrand attack within five minutes of exposure. Since these key issues are not taken into account, the current test standard provides little guidance on roof deck design to mitigate firebrand attack. There is no evidence to suggest that this test standard is a 'worst-case' firebrand exposure.

Naturally, full-scale experiments are required to observe the vulnerabilities of structures to firebrand showers but reduced-scale test methods will serve as the basis for new standard testing methodologies. To this end, new standard test methods that simulate a dynamic firebrand attack are required to expose building materials, not just roof decks, to wind driven firebrand showers [31]. It is necessary to produce a constant firebrand shower for standard test methods for a desired duration.

The NIST Reduced Scale Continuous Firebrand Generator can simply be coupled with a reduced-scale wind tunnel in a similar manner to the present NIST Dragon's LAIR facility and can be used to expose building materials to varying duration firebrand showers and develop a rating system for these materials. For example, different classes of building materials can now be evaluated using the technology developed in this paper. Due to the small footprint of this apparatus, low heat release rate, and low manufacturing cost, it is envisioned that this technology can be used both as a research tool and considered for development as a standard test method provided it is coupled to a wind tunnel facility.

Another key issue is that the firebrand size and mass produced using the newly developed device presented in this paper has been tied to those measured from full-scale tree burns and actual WUI fires. Specifically, the firebrand sizes produced using this device are commensurate with the characteristics of firebrand exposure at a single location during a severe WUI fire in California that destroyed 254 homes [28]. This is 
incredibly critical since empirical characterization of firebrand exposure is extremely limited especially with respect to firebrand size distributions during actual interface fire conditions. Consistently small sizes of windblown firebrands, similar to those generated using this device, were observed by data collection adjacent to a home that survived severe interface fire exposure. This is in stark contrast with the size of firebrands referenced in existing test standards (e.g. ASTM E108 [30]) and wildfire protection building construction recommendations.

Finally, when firebrands contact ignitable fuel beds, they are most likely in a state of glowing combustion, not open flaming. While it is possible for firebrands to remain in a flaming state under an air flow and therefore it is reasonable to assume that some firebrands may still be flaming upon impact, the purpose of this device is to simulate firebrand showers observed in long range spotting and therefore glowing firebrands were desired. Yet, if flaming firebrands are desired, it is a trivial matter to produce these as well.

\section{SUMMARY}

A new experimental apparatus, known as the NIST Reduced Scale Continuous Feed Firebrand Generator (the NIST continuous feed Baby Dragon) was presented. The number flux and mass flux were measured as function of feeding rate to determine optimum conditions to generate steady firebrand showers. It was observed that a feeding rate of 15 pieces $(34.6 \mathrm{~g} / \mathrm{min})$ provided the most constant and uniform continuous firebrand production. The firebrand size and mass produced using the newly developed device presented in this paper has been tied to those measured from full-scale tree burns and actual WUI fires. Based on past ignition studies, continual bombardment of firebrands of the size and mass generated at a feeding rate of 15 pieces $(34.6 \mathrm{~g} / \mathrm{min})$, which corresponds to $0.05 \mathrm{~g} / \mathrm{s}$ of firebrands produced, are capable of igniting fuel beds [32-33]. Specifically, the firebrand sizes produced using this device are commensurate with characteristics of firebrand exposure at a single location during a severe wildland-urban interface (WUI) fire in California that destroyed 254 homes. Due to the small footprint of this apparatus, low heat release rate, and low manufacturing cost, it is envisioned that this technology can be used both as a research tool and considered for development as a standard test method provided it is coupled to a wind tunnel facility.

\section{ACKNOWLEDGEMENTS}

The experiments were conducted in the NIST Large Fire Laboratory (LFL). The assistance of the LFL staff is appreciated (Dr Matthew F. Bundy - Supervisor; Mr Laurean DeLauter and Mr Anthony Chakalis Engineering Technicians). The device was constructed by Mr John R. Shields (EL-NIST), Mr John Lui, a DHS intern assisted with data analysis, and Dr Seul-Hyun Park (former EL-NIST Guest Researcher) designed the control system for the gating system. This research was funded by the Science and Technology Directorate of the US Department of Homeland Security.

\section{REFERENCES}

[1] Maranghides, A., Mell, W.E., A Case Study of A Community Affected by the Witch and Guejito Fires, NIST TN 1635, April, 2009.

[2] Blanchi, R., Leonard, J.E., Leicester, R.H., Lessons Learnt from Post-Fire Surveys at the Urban Interface in Australia. in: Proceedings of the Fifth International Conference on Forest Fire Research, Figueria da Foz, Portugal, 2006.

[3] Cohen, J.D., Stratton, J., Home Destruction Examination, Grass Valley Fire, Lake Arrowhead, CA, USDA Report R5-TP-026 b, 2008.

[4] Albini, F., Spot Fire Distances From Burning Trees - A Predictive Model, USDA Forest Service General Technical Report INT-56, Missoula, MT, 1979.

[5] Albini, F., Transport of Firebrands by Line Thermals, Combustion Science and Technology 32 (1983) 277-288. http://dx.doi.org/10.1080/00102208308923662

[6] Muraszew, A., Fedele, J.F., Statistical Model for Spot Fire Spread, The Aerospace Corporation Report No. ATR-77758801, Los Angeles, CA, 1976.

[7] Tarifa, C.S., del Notario, P.P., Moreno, F.G., On the Flight Paths and Lifetimes of Burning Particles of Wood, Proceedings of the Combustion Institute 10 (1965) 1021- 1037. 
[8] Tarifa, C.S., del Notario, P.P., Moreno, F.G., Transport and Combustion of Fire Brands.' Instituto Nacional de Tecnica Aerospacial "Esteban Terradas", Final Report of Grants FG-SP 114 and FGSP-146, Vol. 2. (Madrid, Spain) 1967.

[9] Tse, S.D., Fernandez-Pello, A.C., On the Flight Paths of Metal Particles and Embers Generated by Power Lines in High Winds and their Potential to Initiate Wildfires, Fire Safety Journal 30 (1998) 333-356. http://dx.doi.org/10.1016/S0379 7112(97)00050-7

[10] Anthenian, R., Tse, S.D., Fernandez-Pello, A.C., On the Trajectories of Embers Initially Elevated or Lofted by Small Scale Ground Fire Plumes in High Winds, Fire Safety Journal 41 (2006) pp. 349-363. http://dx.doi.org/10.1016/j.firesaf.2006.01.005

[11] Woycheese, J.P., Brand Lofting and Propagation for Large-Scale Fires, Ph.D. Thesis, University of California, Berkeley, 2000.

[12] Himoto, K. and Tanaka, T., 2005. Transport of Disk-shaped Firebrands in a Turbulent Boundary Layer. Fire Safety Science 8: 433-444. http://dx.doi.org/10.3801/IAFSS.FSS.8-433

[13] Knight, I.K., The Design and Construction of a Vertical Wind Tunnel for the Study of Untethered Firebrands in Flight, Fire Technology 37 (2001) pp. 87-100. http://dx.doi.org/10.1023/A:1011605719943

[14] Wang, H.H., Analysis of Downwind Distribution of Firebrands Sourced from a Wildland fire, Fire Technology, 47 (2011) pp. 321-340. http://dx.doi.org/10.1007/s10694-009-0134-4

[15] Waterman, T.E., Experimental Study of Firebrand Generation, IIT Research Institute, Project J6130, Chicago, IL, 1969.

[16] Manzello, S.L., Maranghides, A., Mell, W.E., Firebrand generation from burning vegetation, International Journal of Wildland Fire 16 (2007) pp. 458-462. http://dx.doi.org/10.1071/WF06079

[17] Manzello, S. L., et al., Mass and Size Distribution of Firebrands Generated from Burning Korean Pine (Pinus koraiensis) Trees, Fire and Materials 33 (2009) pp. 21-31. http://dx.doi.org/10.1002/fam.977

[18] Waterman, T.E., Takata, A.E., Laboratory Study of Ignition of Host Materials by Firebrands, Project J-6142-OCD Work Unit 2539A, IIT Research Institute, Chicago, IL 1969

[19] Dowling, V.P., Ignition of Timber Bridges in Bushfires, Fire Safety Journal 22 (1994) pp. 145168. http://dx.doi.org/10.1016/0379-7112(94)90070-1

[20] Ellis, P.F., The Aerodynamic and Combustion Characteristics of Eucalypt Bank - A Firebrand Study, PhD Dissertation, Australian National University, Canberra, 2000.

[21] Ganteaume, A., Lampin-Maillet, C., Guijarro, M., Hernando, C., Jappiot, M., Fonturbel, T., PerezGorostiaga, P., Vega, J.A., Spot Fires: Fuel Bed Flammability and Capability of Firebrands to Ignite Fuel Beds, International Journal of Wildland Fire 18 (8) (2009) pp. 951-969. http://dx.doi.org/10.1071/WF07111

[22] Manzello, S.L., Cleary, T.G., Shields, J.R., Yang, J.C., Ignition of Mulch and Grasses by Firebrands in Wildland-Urban Interface (WUI) Fires, International Journal of Wildland Fire 15 (2006) pp. 427-431. http://dx.doi.org/10.1071/WF06031

[23] Manzello, S.L., Shields, J.R., Yang, J.C., Hayashi, Y., Nii, D., On the Use of a Firebrand Generator to Investigate the Ignition of Structures in WUI Fires, In Proceedings of the 11th International Conference on Fire Science and Engineering (INTERLFAM), Interscience Communications, London, (2007) pp. 861-872.

[24] Manzello, S.L., Shields, J.R., Hayashi, Y. and Nii, D., 2009. Investigating the Vulnerabilities of Structures to Ignition from a Firebrand Attack. Fire Safety Science 9: 143-154. http://dx.doi.org/10.3801/IAFSS.FSS.9-143 
[25] Manzello, S.L., Hayashi, Y., Yoneki, Y., Yamamoto, Y., Quantifying the Vulnerabilities of Ceramic Tile Roofing Assemblies to Ignition During a Firebrand Attack, Fire Safety Journal 45 (2010) pp. 35-43. http://dx.doi.org/10.1016/j.firesaf.2009.09.002

[26] Manzello, S.L., Park, S.H., Shields, J.R., Hayashi, Y., Suzuki, S., Comparison Testing Protocol for Firebrand Penetration Through Building Vents: Summary of BRI/NIST Full Scale and NIST Reduced Scale Results, NIST TN 1659, January 2010.

[27] Manzello, S.L., Park, S.H., Shields, J.R., Suzuki, S., Hayashi., Y., Determining Structure Vulnerabilities to Firebrand Showers in Wildland-Urban Interface (WUI) Fires, Proceedings of the Royal Society of London A (in review)

[28] Foote, E.I.D. Liu, J., and Manzello, S.L., Characterizing Firebrand Exposure During WildlandUrban Interface Fires, In Proceedings of Fire and Materials 2011 Conference, Interscience Communications, London, (2011), pp. 479-492.

[29] Bryant, T.J., Johnsson, E.L., Hamins, A., Grove, B.S., Guthrie, W.F., Maranghides, A., Mulholland, G.W., NIST 3 Megawatt Quantitative Heat Release Rate Facility, NIST SP 1007, December, 2003.

[30] ASTM E108 "Fire Standards and Flammability Standards" ASTM International, West Conshohocken, PA, (2003). http://dx.doi.org/10.1520/E0108-10A

[31] Manzello, S.L., and Suzuki, S., Summary of Workshop on Research Needs for Full Scale Testing to Determine Vulnerabilities of Siding Treatments and Glazing Assemblies to Ignition by Firebrand Showers, NIST SP 1111, June 2010.

[32] Manzello, S.L., Park, S.H., and Cleary, T.G., Investigation on the Ability of Glowing Firebrands Deposited Within Crevices to Ignite Common Building Materials, Fire Safety Journal 44 (2009) pp. 894-900. http://dx.doi.org/10.1016/j.firesaf.2009.05.001

[33] Manzello, S.L., Cleary, T.G., Shields, J.R., Maranghides, A., Mell, W.E., and Yang, J., Experimental Investigation of Firebrands: Generation and Ignition of Fuel Beds, Fire Safety Journal 43 (2008) pp. 226-233. http://dx.doi.org/10.1016/j.firesaf.2006.06.010 